\title{
Correction to: Mechanical Reliability and In Vitro Bioactivity of 3D-Printed Porous Polylactic Acid- Hydroxyapatite Scaffold
}

Chander Prakash, Gurminder Singh, Sunpreet Singh (D), Linda Yongling Wu, H.Y. Zheng, Seeram Ramakrishna, and Roger Narayan

\section{Correction to: JMEPEG}

https://doi.org/10.1007/s11665-021-05566-x

The first name of coauthor Gurminder Singh was misspelled (as "Gurmider") in this article as originally published.
The original article has been corrected.

Publisher's Note Springer Nature remains neutral with regard to jurisdictional claims in published maps and institutional affiliations.

The original article can be found online at https://doi.org/10.1007/ s11665-021-05566-x.

Chander Prakash, School of Mechanical Engineering, Lovely Professional University, Phagwara, Punjab 144411, India; Gurminder Singh, School of Mechanical and Materials Engineering, University College Dublin, Dublin, Ireland; Sunpreet Singh and Seeram Ramakrishna, Department of Mechanical Engineering, National University of Singapore, Singapore, Singapore; Linda Yongling Wu and H.Y. Zheng, Department of Mechanical Engineering, Shandong University of Technology, Zibo, China; Roger Narayan, Biomedical Engineering, University of North Caroline, Chapel Hill. Contact e-mail: snprt.singh@gmail.com. 